\title{
Detailed quantification of delta subsidence, compaction and interaction with man-made structures: the case of the NCA airport, France
}

\author{
O. Cavalié, A. Sladen, and M. Kelner \\ Géoazur, Université de Nice Sophia Antipolis, CNRS, IRD, Observatoire de la Côte d'Azur, 250 rue Albert Einstein, \\ 06560 Valbonne, France
}

Correspondence to: O. Cavalié (ocavalie@geoazur.unice.fr)

Received: 20 April 2015 - Published in Nat. Hazards Earth Syst. Sci. Discuss.: 11 June 2015

Revised: 24 August 2015 - Accepted: 31 August 2015 - Published: 8 September 2015

\begin{abstract}
River deltas are dynamic coastal systems and their evolutions are closely monitored as it often concentrates vital natural resources for the surrounding areas. Many deltas worldwide experience subsidence due to geological processes (sediment loading and compaction) or human activities (groundwater or hydrocarbon extraction, land reclamation). This causes shoreline erosion or wetland loss which represent serious issues for the population. In this study we investigate the dynamic of the Var delta (France) where reclaimed lands over sea have been built to host the Nice côte d'Azur airport (NCA). Actually, the stability of this infrastructure is a permanent concern since, in 1979, a newly built extension of the runway platform collapsed in the sea, causing important damages. The project of land extension stopped, but the present airport platform is still located on reclaimed land. Factors that can trigger such catastrophic landslide are thought to be linked to the delta activity and the artificial airport platform load. We used, therefore, Envisat InSAR data to measure accurately the ground deformation of the area that includes the Var delta and NCA airport. Combining data from ascending and descending orbits, we estimated the east-west and vertical components of the deformation and obtained very accurate displacement rate (with a $1 \sigma$ error of $0.25 \mathrm{~mm} \mathrm{yr}^{-1}$ ). We found that nearly all the deformation is vertical and impacts the whole Var delta. The Var valley subsides at a very low rate $\left(0.5-1 \mathrm{~mm} \mathrm{yr}^{-1}\right)$ but downstream the subsidence rate increases and a clear jump is observed at the transition with the reclaimed lands $\left(1-2 \mathrm{~mm} \mathrm{yr}^{-1}\right)$. On average, the reclaimed lands subside at
\end{abstract}

$3 \mathrm{~mm} \mathrm{yr}^{-1}$. Since the subsidence rate increases in correlation with the sediment thickness, we interpret it as the compaction of the delta quaternary sedimentary wedge. In addition, three areas subside faster (between 5 and $10 \mathrm{~mm} \mathrm{yr}^{-1}$ ), with one calling for more attention as it is the largest and overlooks the steep Var canyon. The progressive increase of subsidence rates toward the sea also suggests that the underwater parts of the margins could subside at rates well above $10 \mathrm{~mm} \mathrm{yr}^{-1}$.

\section{Introduction}

More than 300 million people live on river deltas (Ericson et al., 2006) and a major environmental issue is land subsidence. With eustatic sea-level rise, this phenomena causes shoreline erosion, wetland loss, flow inversion in the drainage watercourses, or salt water intrusion (Syvitski et al., 2009). Therefore, accurate quantification of delta subsidence is important data to anticipate the ensuing processes and to protect the exposed population. For example, Milliman et al. (1989) used estimates of eustatic sea-level rise and ground subsidence to estimate land loss for three future scenarios in the Nile and Bengal deltas.

Ground subsidence is also problematic for the stability of infrastructures as bridges, dams or airports. For coastal cities with limited flat lands, it is common practice to have airports partly built on land reclaimed from the sea. This is the case of many international airports such as Haneda and Kansai airports in Japan, the Chek Lap Kok airport in Hong-Kong 


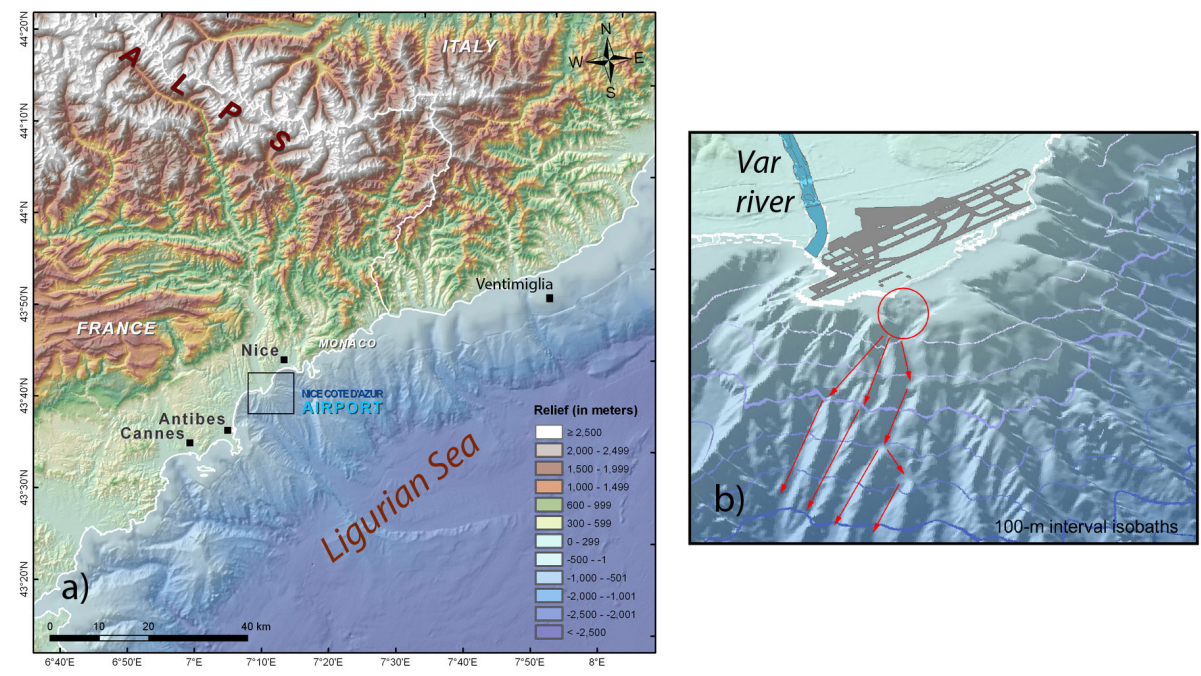

Figure 1. (a) Map of Nice area showing the large topographic gradient between the southern Alps and the offshore margin of the Ligurian sea (more than $4000 \mathrm{~m}$ elevation drop over $40 \mathrm{~km}$ ). The black square indicates the location of the close-up shown in (b). (b) Zoom on the Nice Côte d'Azur airport platform with a 3-D perspective. The red circle shows the airport extension area which collapsed in 1979 and contributed to the tsunami. The path of the landslide is indicated with red arrows.

or the Incheon airport in South Korea. Although convenient, airport platforms built on reclaimed lands might, over time, lead to stability concerns and/or particular exposure to searelated natural hazards such as storm or tsunami surges.

The Nice Côte d'Azur international airport (NCA), southeast of France, is one such airport built on reclaimed land. It is located on the North Ligurian Basin (Mediterranean Sea) at the end of the Var river delta (Fig. 1). Most of the airport's offshore extension was built in the late seventies. The original project was to reclaim land on the narrow coastal shelf (1-2 km wide) to build new landing tracks and a major commercial harbour on the edge of those new runways. However, the large harbour seawall disappeared in a major submarine landslide in October 1979 (Fig. 1). The volume of the surge was estimated to be 150 million $\mathrm{m}^{3}$ (AssierRzadkieaicz et al., 2000), rupturing a communication cable $105 \mathrm{~km}$ from the source and generating a 2-3 m high local tsunami which killed nine people, mostly on the construction site (Assier-Rzadkieaicz et al., 2000; Sahal and Lemahieu, 2011; Ioualalen et al., 2010). The exact scenario of the landslide remains a topic of debate (Anthony and Julian, 1997; Mulder et al., 1997; Assier-Rzadkieaicz et al., 2000; Dan et al., 2007; Kopf et al., 2010; Sultan et al., 2010): was it triggered by the exceptional rainfalls in the previous weeks? Did the instability of the newly man-made structure initiate the landslide and turbidity currents? Or is it due to sensitive clay layer failure? At least, the landslide was not triggered by earthquakes at that time which is nevertheless another possible triggering mechanism in this region of moderate seismic activity (Mulder et al., 1994). However, the evaluation of the margin activity from 1991 to 2011 suggests that fresh-water outflow might indeed be a main triggering mechanism for the more recent landslides (Kelner et al., 2014). The construction of the harbour was cancelled after the 1979 catastrophe but the extension of the airport platform, which had already been completed, was used to build the two main runways, still in use today (Fig. 1). Several studies, focused on the slope of the Nice margin, have collected evidence from core samples (Cochonat et al., 1993; Migeon et al., 2011; Hassoun et al., 2014) or high-resolution bathymetry (Migeon et al., 2012; Kelner et al., 2014) of several past failure events suggesting that the airport platform might be exposed and unstable. Concerns were raised after a series of studies using bathymetry data, sediment cores and CPTU data (Dan et al., 2007; Leynaud and Sultan, 2010; Sultan et al., 2010) which led the authors to conclude that the slopes of the airport platform were probably highly unstable (Sultan et al., 2010). Since the 1979 airport extension (which doubled the size of the airport), NCA became a critical lever for the economic development of the French Riviera (11M passengers in 2012, third busiest airport in France), in an area whose terrestrial access is otherwise limited by the sea and the Alps (Fig. 1). All these evolutions have turned the stability of the NCA slopes into a major societal and economic concern.

In this study, we use synthetic aperture radar interferometry (InSAR) to detect potential deformation of the Var valley area. Due to the poor penetration of radar waves into water, our study focuses only on the inland delta and NCA airport deformation, but also gives hints regarding its offshore extension. We are particularly interested in observing a possible link between the global delta dynamic and the suspected deformation on the NCA platform. Actually, Var river is by far the most important river of the French Riviera and it is, in particular, characterized by torrential discharge (up 

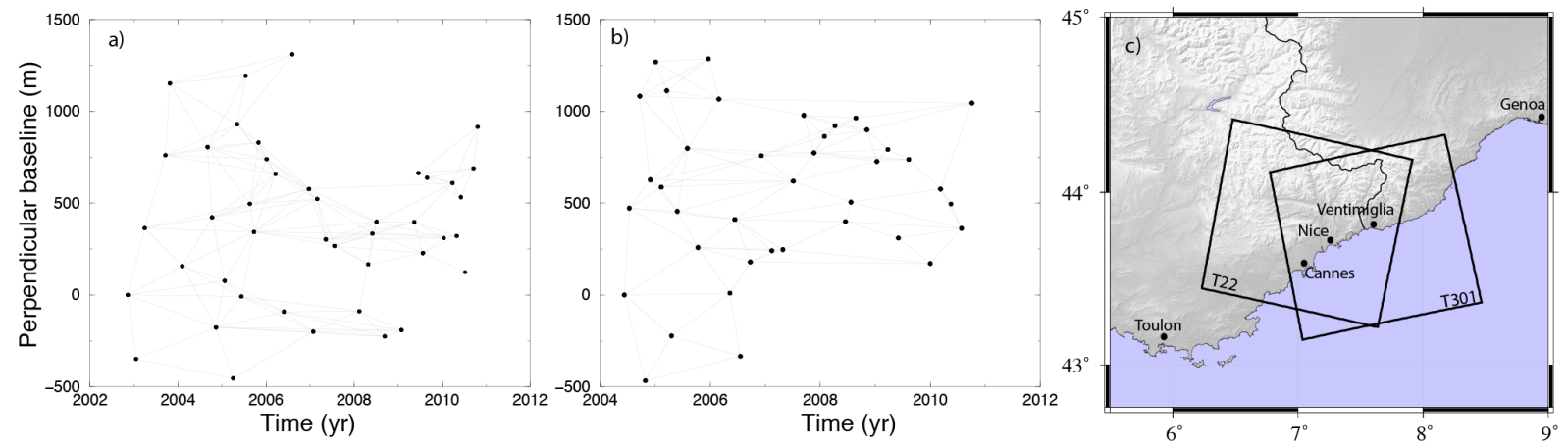

Figure 2. Relative position of Envisat orbits plotted as a function of image acquisition date for (a) ascending track 301 and (b) descending track 22. Grey lines show the interferograms included in the time series analysis. (c) Spatial coverage of tracks 301 and 22 are represented by the black squares.

to $3770 \mathrm{~m}^{3} \mathrm{~s}^{-1}$ during the catastrophic 1994 flooding event) (Anthony, 2007), that is one of the proposed scenarios to explain the 1979 submarine landslide (Dan et al., 2007; Kopf et al., 2010). In order to do a comprehensive analysis of the whole margin, this inland ground motion can be compared to submarine analysis that studied the sea-floor deformations (Kelner et al., 2014).

To track the deformation evolution through time and increase the signal-to-noise ratio of the averaged velocity over the period 2003-2011, we perform a time series analysis of the SAR images that has been successfully used to measure centimetric ground motion related to volcanoes (Hooper et al., 2008), ground subsidence related to surface load changes (Cavalié et al., 2007), urban subsidence due to ground compaction (López-Quiroz et al., 2009), or active tectonic (Cavalié and Jónsson, 2014).

\section{Data and InSAR method}

We used the Envisat satellite data archive provided by the European Space Agency (ESA) to measure the deformation around the NCA airport from both descending and ascending orbits. For the period 2003-2011, 47 images have been acquired along descending track 22 and 40 images along ascending track 301 (Fig. 2). Images from ascending and descending tracks overlap from Cannes, France, to Ventimiglia, Italy (Fig. 2c).

We generated ground displacement time series from interferograms using the New Small BAseline Subset (NSBAS) processing chain (Doin et al., 2012). This chain is based on the ROI_PAC (Repeat Orbit Interferometry Package) software (Rosen et al., 2004). The main idea consists in limiting both the temporal and spatial baseline between the images that will be combined to compute the interferograms in order to optimize the interferometric phase coherence and keep the highest possible number of pixels for the deformation analysis. Figure $2 \mathrm{a}$ and $\mathrm{b}$ show the network of interferograms based on the image acquisition configuration. Inter- ferograms are corrected for orbital and topographic components using DORIS and the 3 arcsec SRTM DEM (Farr and Kobrick, 2000), respectively. To help the phase unwrapping, interferograms are filtered using an adaptive filter (Goldstein and Werner, 1998) and slightly downsampled by pixel multilooking with 2 looks in range and $2 \times 5$ looks in azimuth. The resulting pixel spacing is $\sim 40 \mathrm{~m} \times 40 \mathrm{~m}$. The interferogram coherence stays good along the coast, thanks to the strong reflections of the buildings, and very poor in the up-country due to the steep slopes of the mountains and the vegetation that covers most of the area. We used SNAPHU (StatisticalCost Network-Flow Algorithm for Phase Unwrapping) to unwrap interferograms. To avoid dealing with the very complex unwrapping process in the mountainous area, we take only a small subset of the images around the airport. This step allows to greatly speed-up the computation of the interferograms. To process the ground displacement time series, it is important that all interferograms are properly referenced. Any stable area (i.e., area that is not deforming and that keeps a good phase coherence through time) can be set as a reference. However, as phase propagation delays affect pixels randomly, a too small area, even stable, should not be used as a reference as it might be off by several radians. We used a constrained least-square inversion (Doin et al., 2012) in order to derive the surface displacement rates from the interferograms. A smoothing operator is applied to limit phase variations due to turbulent atmospheric delays. Displacement rate of the ground are estimated by the linear component of the time series result for each pixel. We therefore measured the ground displacement rates from two point of views (or line of sights, LOS) corresponding to the ascending and descending orbits. As the satellite LOS has an average angle of $23^{\circ}$ with the vertical, the measurements are more sensitive to vertical displacements. Moreover, Envisat satellite has a mostly north-south orbit (azimut of $\sim 13^{\circ} \mathrm{N}$ ) and has a side-looking acquisition mode. InSAR measurements are, thus, almost insensitive to north-south ground deformation. In a referential where the east-, north- and up-axis are defined positive, the 

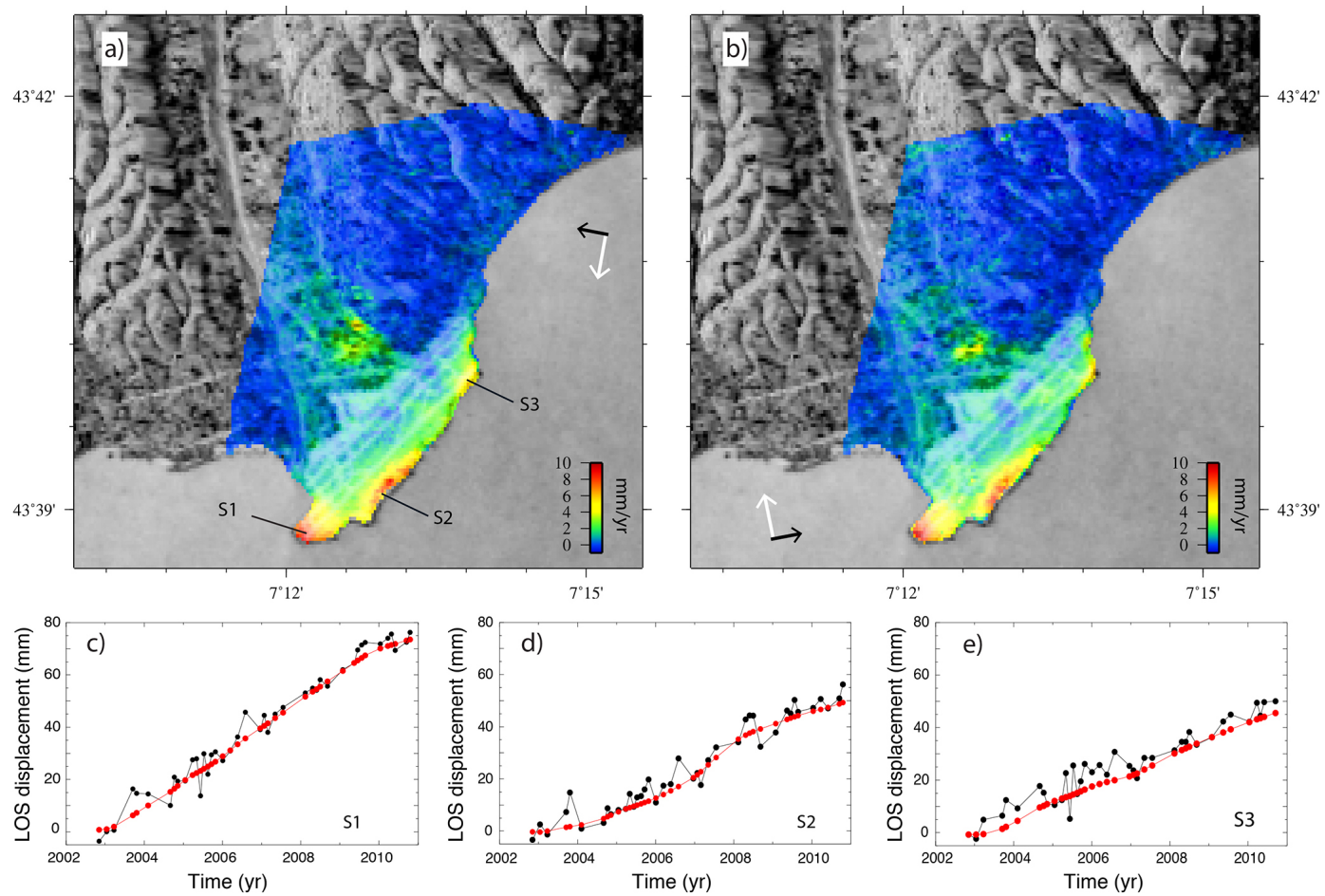

Figure 3. Ground velocity maps from InSAR time series analysis in $\mathrm{mm} \mathrm{yr}^{-1}$ measured along the satellite line of sight (LOS) direction (black and white arrows show the LOS and flight directions, respectively). For descending track 22 (a) and ascending track 301 (b), velocities are shown positive in the direction away from the satellite (black arrows). Time series of the ground displacement (shown in c-e) for three pixels located in S1, S2, and, S3. Black and red lines represent the ground displacement between 2003 and 2011 without or with smoothing, respectively.

mean line of sight vectors are $(0.381 ; 0.088 ;-0.921)$ and $(-0.381 ; 0.088 ;-0.921)$ for the ascending and the descending orbits, respectively. Therefore, one can retrieve the east component and the mostly vertical (with a bit of north) component of the ground displacement in combining both LOSs.

\section{Results of the time series InSAR analysis}

Figure $3 \mathrm{a}$ and $\mathrm{b}$ shows the averaged ground velocity maps obtained independently along tracks 301 (descending orbit) and 22 (ascending orbit). Two results jump out: (i) the great similarity between the ascending and descending velocity maps, and (ii) the presence of three areas located along the edge of the airport platform (labelled S1, S2, and S3 on Fig. 3a) moving away from the satellite. Moreover, as shown by the LOS arrows, the view angles between the ascending and descending tracks differ mostly in the sign of the east component. Therefore, most of the deformation seems vertical. The fusion of those maps can be done in combining the two LOSs (either by subtraction or addition) in order to separate the east component and the quasi-vertical component of the ground displacement. As expected, we find that the ground motion is essentially vertical (Fig. 4a), and not horizontal (i.e., in the east-west direction) (Fig. 4b).
The east-west component is mostly around zero, displaying a spatially coherent signal only in a few localized areas (Fig. 4b). Indeed, the noise level of the horizontal component might seem large compared to that of the vertical component (Fig. 4a) but, as the LOS vector makes a relatively large angle with horizontal $\left(67^{\circ}\right)$, when InSAR signal is projected into the east component, the noise gets amplified by a factor $\sim 1 / \sin \left(23^{\circ}\right)$. Hence, the horizontal motion cannot be interpreted with the same level of confidence as the vertical motion. Where there is coherent horizontal motion, it does not correlate with well identified ground structures and we interpret these signals as noise. The only exception is the eastward motion along the offshore edge of the runway platform because the signal is spatially coherent. This area is very narrow (about 1 pixel wide) and could represent the response of the platform seawall (that is made of big concrete blocks) to the wave forces. On the other hand, the vertical component shows very clear patterns of deformation (Fig. 4a), with a general trend of subsidence over the whole studied area and a few localized areas of more intense subsidence. All these areas of more intense deformation are on the edges of the airport platform. The largest subsidence rate is located on the southern tip of the platform corresponding to the beginning of the landing tracks ( $\mathrm{S} 1$ on Fig. 3a): 

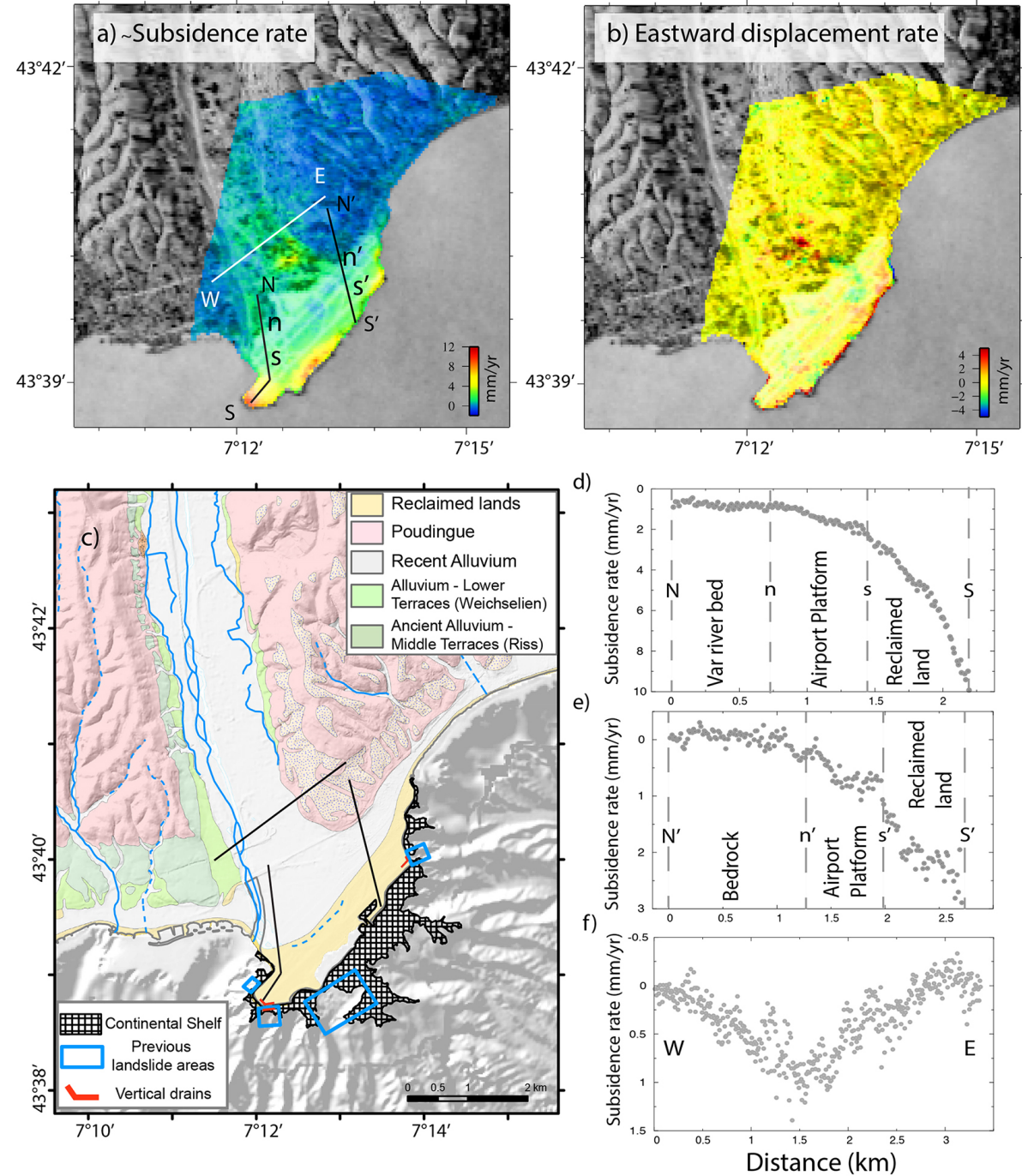

Figure 4. Near vertical component (a) and east component (b) of the ground displacement rate (in $\mathrm{mm} \mathrm{yr}^{-1}$ ) obtained by combining ascending and descending track measurements. (c) Geological map extracted from "BRGM 50k standardized". The topography is from "GO_06 juin 2009" and bathymetry results from compilation of marine campaign data. Observed subsidence rates along N-S (d, e) and E-W (f) profiles are shown (profile locations in Fig. 4a and c). InSAR data (gray dots) are comprised within a $2 \mathrm{~km}$ wide box around the profile lines.

this area, roughly $500 \mathrm{~m} \times 500 \mathrm{~m}$ and surrounded on all three sides by water, has a subsidence rate that progressively increases from 4 to $9.5 \mathrm{~mm} \mathrm{yr}^{-1}$ near its offshore edge (Fig. 4a and c). A second patch of subsidence (S2 on Fig. 3a), about $1 \mathrm{~km}$ northeast of $\mathrm{S} 1$, has a similar but slightly lower rate of subsidence $\left(8.5 \mathrm{~mm} \mathrm{yr}^{-1}\right)$ and is elongated along the edge of the platform. Finally, a third much smaller patch of deformation (S3 on Fig. 3a) with $6 \mathrm{~mm} \mathrm{yr}^{-1}$ of motion is detected on the eastern corner of the airport, near the end of the landing tracks. Times series for these three patches of highest subsidence show linear ground displacements over the whole period studied (2003-2011) with little scatter between measurements at each interval of the time series analysis (Fig. 3c-e).
But these patches of more intense deformation are part of a larger scale subsidence pattern (green area on Fig. 4a) starting from zero about $4 \mathrm{~km}$ upstream of the Var valley, progressively increasing to a few $\mathrm{mm} \mathrm{yr}^{-1}$ toward the airport, and then strongly increasing across the airport platform (runway tracks). While the Var riverbed subsidence rates are small, there are arguments to believe the subsidence is real: the pattern is spatially coherent and the amplitudes are clearly above the pixel dispersion. A profile across the Var riverbed (Fig. 4f) shows that the pixels dispersion is less than $0.5 \mathrm{~mm} \mathrm{yr}^{-1}$ and the subsidence rate goes back to $0 \mathrm{~mm} \mathrm{yr}^{-1}$ on the edges of the valley. Moreover, the displacement rate dispersion over areas that are assumed to be stable (i.e., no displacement) shows a Gaussian distribution centered around zero and with a standard deviation 

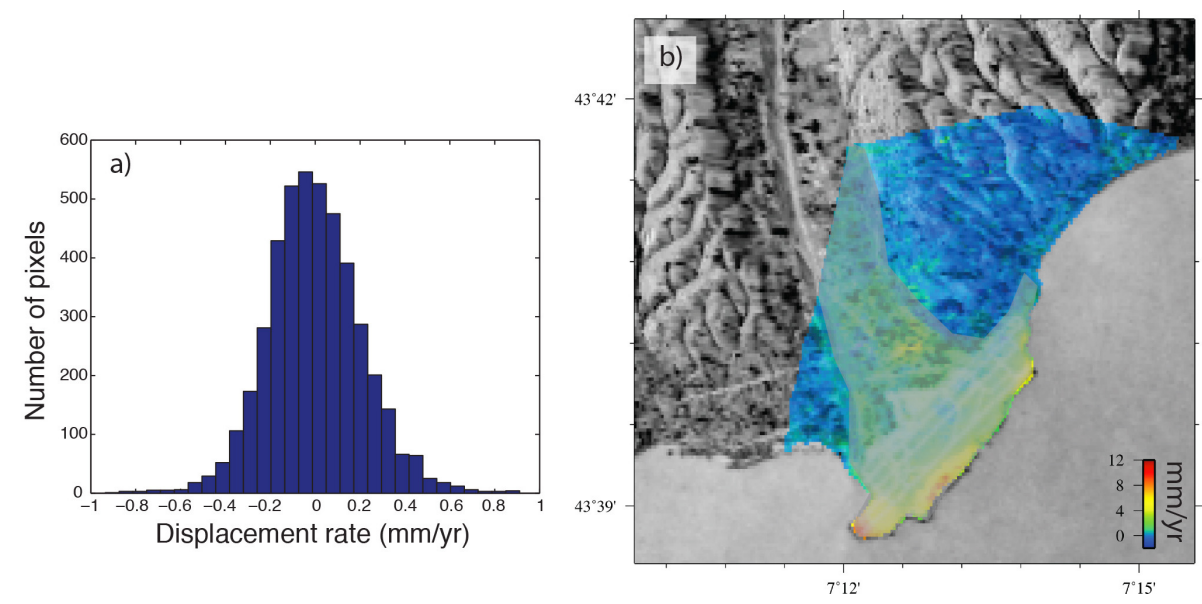

Figure 5. (a) The ground displacement rate, measured over the stable areas, shows a gaussian distribution centered around zero and with a standard deviation of $0.25 \mathrm{~mm} \mathrm{yr}^{-1}$. (b) Map showing in grey the area which has been masked (Var riverbed and the airport platform) to estimate the measurement dispersion.

of $0.25 \mathrm{~mm} \mathrm{yr}^{-1}$ (Fig. 5). As there is no reason that this noise distribution changes for the airport platform, we assume that $1 \sigma$ error of $0.25 \mathrm{~mm} \mathrm{yr}^{-1}$ can be applied to the rest of the map. To investigate further this large subsidence pattern, we drew two profiles from the riverbed (profile N$\mathrm{S}$ ) or coastal range (profile $\mathrm{N}^{\prime}-\mathrm{S}^{\prime}$ ) to the edge of the delta (Fig. $4 \mathrm{~d}$ and e). The profiles reveal a differential motion between the last 3-4 km of the Var riverbed subsiding at about $1 \mathrm{~mm} \mathrm{yr}^{-1}$ (segment $\mathrm{N}-\mathrm{n}$, Fig. 4d) and the stable surrounding coastal range (segment $\mathrm{N}^{\prime}-\mathrm{n}^{\prime}$, Fig. 4e). This difference is also clearly visible on the vertical velocity map (Fig. 4a) with the green-blue contrast between subsiding and stable areas respectively. This contrast matches very well the geology of the area (Fig. 4c). But it is only at the transition with the delta, which essentially corresponds to the airport area, that the subsidence rates become really large. Along profile $\mathrm{n}-\mathrm{S}$, which reaches the patch $\mathrm{S} 1$ of largest subsidence, the rate increases from 1 to $9 \mathrm{~mm} \mathrm{yr}^{-1}$ over a distance of only $1.5 \mathrm{~km}$ (Fig. 4d). Further north on the platform, where the gradient of subsidence rate is the smallest (profile $\mathrm{n}^{\prime}-\mathrm{S}^{\prime}$ ), there is still an increase of $3 \mathrm{~mm} \mathrm{yr}^{-1}$ over $1.5 \mathrm{~km}$ (Fig. $4 \mathrm{e}$ ).

\section{Discussion}

\subsection{Origin of the subsidence}

The InSAR time series analysis reveals a clear subsidence across the studied area, with a moderate and progressive increase of the subsidence in the last few kilometres of the Var riverbed transitioning to larger subsidence rates $\left(4 \mathrm{~mm} \mathrm{yr}^{-1}\right.$ with locally higher values up to $10 \mathrm{~mm} \mathrm{yr}^{-1}$ ) in the last couple of kilometres across the aerial platform. Although the viewing angles of the Envisat radar satellite do not allow to resolve the north-south motion, the absence of large-scale horizontal motion on the east-west component (Fig. 4b) sug- gests that the motion of the delta is almost purely vertical. One exception is a very thin line (1-2 pixels wide) of eastward motion detected on the edge of the airport track but we suspect that it is related to re-mobilization of the large concrete blocs during the strong winter storms. This hypothesis is supported by the steep submarine morphology.

To understand the origin of this subsidence, we compared its location with the geologic map of the area (Fig. 4c). The comparison reveals a remarkable spatial correlation between the subsiding areas and the geological units (Fig. 4a and c), where the large-scale subsidence is limited to the quaternary alluvium deposits of the delta and Var riverbed. On both sides of the riverbed, where the transition from alluvium to conglomerate occurs (poudingue), the subsidence rate quickly drops to zero (Fig. 4f). The conglomerate unit dominates the regional foothill geology and appears to be very stable across our studied area with a rate of $0 \pm 0.25 \mathrm{~mm} \mathrm{yr}^{-1}$ (Fig. 5). This high correlation between subsidence and geology points to a unique large-scale process that affects the end of the Var riverbed and the delta.

Several processes are known to cause subsidence. Tectonics is one of them (e.g. Dokka (2006) discusses the role of a fault on the subsidence of the Mississippi delta) and needs to be considered given that the Ligurian margin is characterized by active deformation (e.g. Larroque et al., 2011). The deformation of the margin, associated to moderate seismicity (Courboulex et al., 2007), is mostly seen through a set of thrust faults at the foot of the continental slope which likely hosted the 1887 earthquake rupture of which the magnitude is estimated around $M_{\mathrm{w}}=6.8-6.9$ (Larroque et al., 2012). However, in this part of the margin, the main faults identified by morpho-geological studies are oriented parallel to the margin (Larroque et al., 2011) and are thus not compatible with a motion restricted to the sole riverbed. It also seems unlikely that a slip on a hypothetical fault would cause a steady 


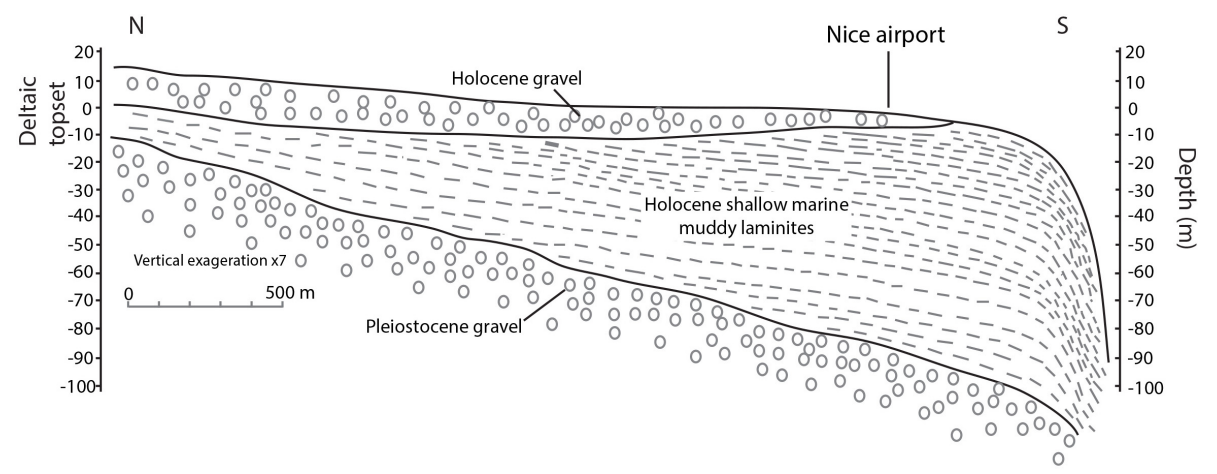

Figure 6. Schematic N-S cross-section of the Var delta deposits (on- and offshore). Figure modified after Dubar and Anthony (1995) and Dan et al. (2007).

subsidence over the 8-year period of our measurements and not show better in the morphology. Salt tectonic also took place deeper in the basin. Salt creep causes very large landslides at the foot of the margin (Hassoun et al., 2014). But these deep basin movements are difficult to link with surface deformation limited to the Var riverbed.

If it is not a tectonic movement origin, a shallow local process is most likely causing the subsidence. Because the subsidence pattern has a very large and consistent extent, it is unlikely related to groundwater extraction or permanent anthropogenic modifications which have affected the area in the last 60 years: namely the reclamation of the airport landing tracks or the severe channelization of the Var river which involved construction of several dams, large-scale aggregate extraction or water pumping (Anthony and Julian, 1997). Yet it remains possible that these anthropogenic modifications contribute to the subsidence rates at a smaller scale. Because the subsidence is well correlated with the Var riverbed and delta alluviums, and decreases with distance away from the shoreline, we argue that consolidation of the sediments is the primary cause of the observed ground motion. Indeed, many of the world's largest river deltas are primarily sinking under the effect of sediment compaction (Syvitski et al., 2009). Examples include the Fraser river delta in Western Canada (Mazzotti et al., 2009), the Mississippi delta in the USA (Törnqvist et al., 2008), the Po delta in Italy (Teatini et al., 2011) or the Ganges-Brahmaputra delta in Bangladesh (Higgins et al., 2014).

\subsection{Deltas and sediment compaction}

In the stratigraphic cross-section of the Var delta (Fig. 6, adapted from the reconstruction work of Dubar and Anthony, 1995; Stegmann et al., 2011), we see that the delta is composed of a Pleistocene basement overlain by Holocene deposits. The thickness of the Holocene superficial strata is maximum offshore by the shelf break $(100 \mathrm{~m})$ and decreases landward over a distance of about $4 \mathrm{~km}$ : this distance to the shore corresponds to the transition between the Var riverbed and the delta, where the deltaic topset starts to be dominated by gravels as expected for a braided bedload channel. At this distance from the shore, the superficial gravel deposits merge with the basal fluvial Pleistocene gravels. The resulting Holocene wedge, which took shape before the Var delta was anthropized, is made of a thick succession of muddy laminites and thin peat interbeds resulting from brackish delta-plain and fluvial overbank deposits (Dubar and Anthony, 1995). Looking at the spatial extent of the Holocene wedge, we find that it matches our documented aerial subsidence pattern by tapering over a distance of about $4 \mathrm{~km}$ from the shelf break. This spatial correlation suggests that the subsidence of the Var delta is mainly controlled by the compaction of these Holocene strata. Since the temporal decrease of subsidence rate typically follows an exponential curve with a relatively short time constant (likely shorter than 100 years) (Terzaghi and Peck, 1967), it seems unlikely that compaction of the basal Pleistocene strata could explain the 4-10 $\mathrm{mm} \mathrm{yr}^{-1}$ of compaction rate (CR) observed at the surface. We thus conclude that the subsidence is mainly related to the compaction of the Holocene wedge as inferred for other deltas such as the Po, Mississippi, Fraser or GangesBrahmaputra deltas (Mazzotti et al., 2009; Törnqvist et al., 2008; Teatini et al., 2011; Higgins et al., 2014, e.g.). Moreover, InSAR data show here an increase of the subsidence rate from inland to the coastline that correlates well with the increase of the Holocene sediment thickness.

Wetland and delta compaction with high CR are often associated with the presence of peat because its decomposition can cause fast compaction in the earliest stage of its formation and burial (Allen, 1995; Long et al., 2006; Törnqvist et al., 2008). This explains why the compaction was linked to the superficial Holocene layers in most of these previously mentioned studies about delta subsidence. In the case of the Var delta, the peat deposits are interlayered with muddy laminites so only compaction tests on core samples could isolate the contribution of each type of deposit to the overall compaction process. This process might also be influenced by the flow of fresh water in the permeable sandy 
layers of the Holocene wedge (Stegmann et al., 2011) that is observed here by the presence of numerous freshwater springs on the shelf slope (Guglielmi, 1993; Stegmann et al., 2011). In any case, our results confirm the general trend that Holocene deposits control delta subsidence, with a greater contribution from the superficial layers that are often composed of a large fraction of peat and clay.

InSAR time series reveals subsidence rates of up to $10 \mathrm{~mm} \mathrm{yr}^{-1}$, but those values are limited to few areas of greater deformation and localized along the platform edge. Outside of those areas, the maximum subsidence rate on the platform reaches 3-4 $\mathrm{mm} \mathrm{yr}^{-1}$ at the coastline (Fig. 4e). These CR values are in the range of what it is observed for modern deltas: $1-2 \mathrm{~mm} \mathrm{yr}^{-1}$ for the Fraser, Nile and Mississippi deltas (Mazzotti et al., 2009; Wöppelmann et al., 2013; Törnqvist et al., 2008) and up to $15-18 \mathrm{~mm} \mathrm{yr}^{-1}$ in some parts of the Po and Ganges-Brahmaputra deltas (Teatini et al., 2011; Higgins et al., 2014). Contrary to those studies (except for the Po delta that seems to behave similarly), the CR increases until the coastline. As the large-scale compaction gradient observed across the Var delta unlikely stops abruptly at the coastline, it probably continues to increase offshore over the remaining distance $(500 \mathrm{~m}$ to $1.5 \mathrm{~km})$ that separates the airport edge from the shelf break (Fig. 1). Presently, there is no observation to quantify the deformation rates of the underwater platform with a centimetric precision. CPTU measurements made offshore suggest that the most critical conditions for the stability of the shelf concern sediments down to $30 \mathrm{~m}$ below the seafloor (Dan et al., 2007). $30-45 \mathrm{~m}$ below the seafloor also corresponds to the average depth of the 1979 landslide.

\subsection{Stability of the high subsidence rate areas}

In addition to the large-scale subsidence, we observe three areas (S1, S2, and S3) along the platform edge with higher displacement rate. We now investigate if these patches reflect processes other than compaction. We are also interested in knowing whether those localized areas inland could reflect a broader scale phenomenon that propagates offshore.

To better understand the possible origin of these patches, we compiled a series of aerial photos at different stages between 1945 (i.e., before any significant lands were reclaimed from the sea) and 2004 (Fig. 7). These aerial photos indicate that the S2 patch corresponds to groynes fields reclaimed post 1979. Because this area is on the edge of the platform and was back filled after the 1979 airport extension, it might not have been filled with the same type of material or dynamically compacted as the rest of the platform (dynamic compaction of the landing tracks was done with a $130 \mathrm{t}$ weight dropped from $22 \mathrm{~m}$ high; Ollié, 1982). The strong correlation of the S2 subsidence pattern with the past groynes fields suggests that these high subsidence values are localized and might not correspond to the edge of an offshore area with higher subsidence rates. Yet, the S2 patch is facing a wide promontory of the underwater shelf (Fig. 4c), on the side of which the 1979 landslide occurred.

Patch S3 is located on the northeastern corner of the landing tracks. It has a much smaller spatial extent than $\mathrm{S} 1$ and S2 $\left(0.05 \mathrm{~km}^{2}\right.$ for S3 compared to $0.25 \mathrm{~km}^{2}$ for S1 and S2) and a subsidence rate of about $6 \mathrm{~mm} \mathrm{yr}^{-1}$, which is about half of the S1 values. Contrary to other sections of the coastline, we see in the bathymetry data (Fig. 1b) that this edge of the airport platform reaches the shelf break. This narrowing of the shelf corresponds to the presence of a relatively small offshore scarp and chute. We know from the differential bathymetry (Kelner et al., 2014) that this scar is indeed a landslide scarp which actively migrated upslope sometime during the period 1967-1999 to reach the shelf break and affect the airport embankment. This type of superficial slope failure is typical of the slopes surrounding the NCA shelf, with concave-up topographic profile and very steep slopes $\left(15-20^{\circ}\right)$ (Migeon et al., 2011). The ensuing bathymetry campaign covering the periods 1999-2006-2011 (Kelner et al., 2014) did not document further extension of the chute. Because there is no clear fluctuation in the displacement time series (Fig. 3e), the subsidence in S3 is probably an indirect response of the ground following the ancient erosion activity of the scar. The retreat of the shelf break could promote compaction by lowering the lateral support and providing more efficient paths for the expulsion of porepressure. While this process could favour instability, the spatial extent of the subsidence and the size of the scar are quite limited. Finally, it is worth noting that S3 corresponds precisely to the location where 566 vertical drains have been installed at $50 \mathrm{~m}$ depth to decrease the interstitial pressure in order to stabilize and compact the sediment input (Ollié, 1982). Interestingly, the other place where drains (596) have been set up is located on S1 (Fig. 4c).

Contrary to the S2 area, which remains a few hundred metres away from the shelf break, the S1 deformation area corresponds to a promontory on the southwestern end of the landing track. It is surrounded by steep canyons on threequarters of its periphery and the distance to the slope break is often smaller than $100 \mathrm{~m}$. Using differential bathymetry, Kelner et al. (2014) have shown that this part of the margin has recently experienced fast morphological changes. Between 1999 and 2006, a strong erosion phase took place and eroded part of the marine airport embankments at the southern point of S1. Around the same place, a landslide, located $100 \mathrm{~m}$ seaward, also reduced the continental shelf up to $30 \mathrm{~m}$. On the other hand, after 2006 this area experienced a much smaller activity with for instance, only sediment deposition around the S1. These strong and rapid changes in aggradation-erosion around the $\mathrm{S} 1$ area can be explained firstly by the proximity of the Var canyon, the link rivercanyon, and by the steep slopes of chutes (Fig. 4c). The Var is the main river of the northern Ligurian margin and is characterized by catastrophic discharge events, typically during fall and spring (Migeon et al., 2011; Guglielmi, 1993): for in- 

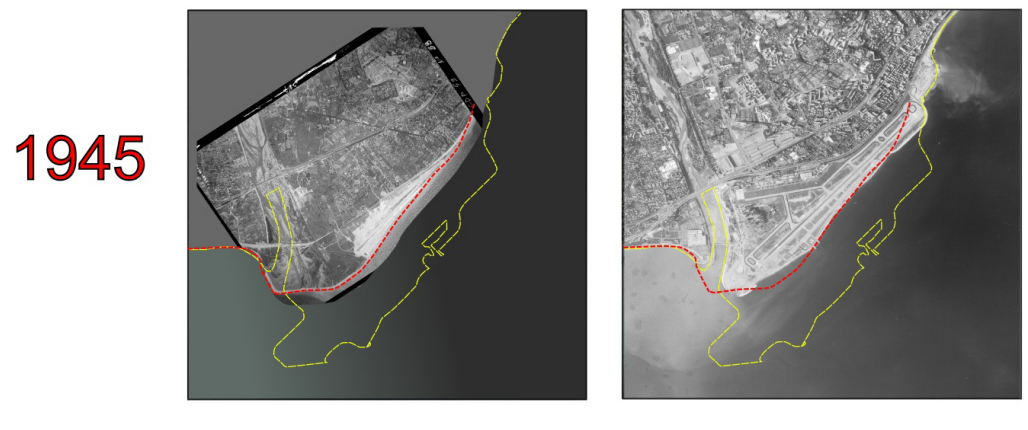

\section{1}
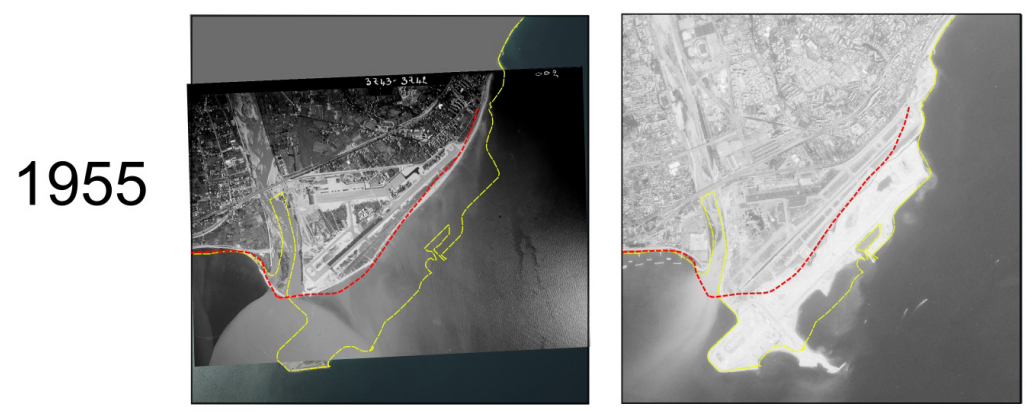

\section{9}
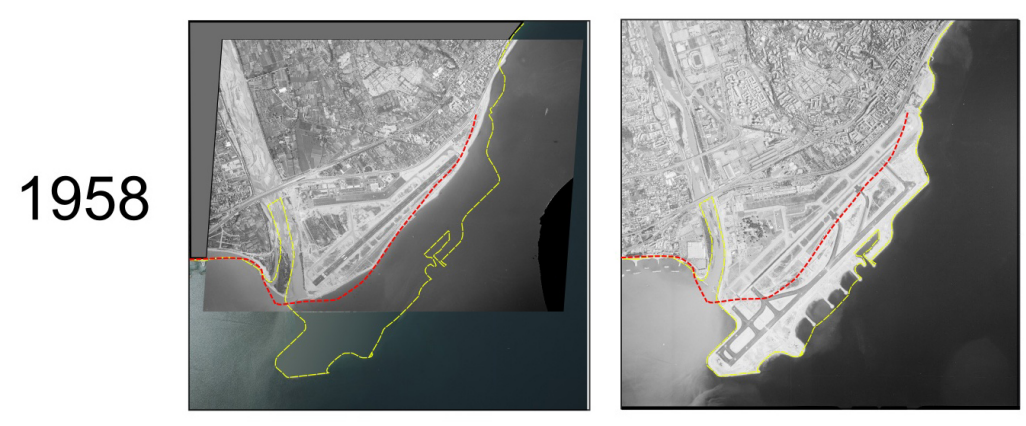

\section{3}
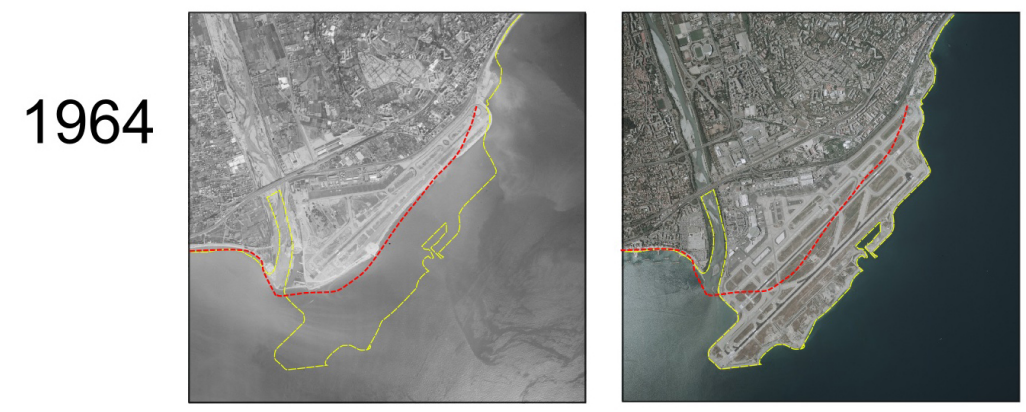

\section{4}

Figure 7. Sequence of aerial photos from 1945 to 2004 showing the evolution of the contour of the NCA airport (that has not changed since then). On all photos, the 1945 coastline contour is reported as a red dashed line and the actual contour as a yellow dashed line. The 1979 photo shows the extension of the newly built seawall before it collapsed into the sea, in October 1979 (photo credit: geoportail.ign.fr).

stance, the Var river had a mean flow value of $751 \mathrm{~m}^{3} \mathrm{~s}^{-1}$ the week before the 1979 landslide (Anthony and Julian, 1997).

The InSAR measurements period (2003-2011) overlaps with the periods studied by differential bathymetry (19992011), but does not identify the change of activity detected on the margin around the S1 promontory since the subsidence rate is steady over the whole period (Fig. 3c). Hence, if the erosion process has any direct impact on the subsidence of the promontory, it is of very small amplitude and does not seem to directly affect the long-term compaction trend. However, the rapid changes in the bathymetry can steepen and thus undermine the slopes supporting the upper part of the shelf. Moreover, the rework of the flanks around the S1 promontory and the large surface exposure to the seawater 
could intensify the dissipation of excess pore-pressure, that is usually the primary process behind compaction (Terzaghi and Peck, 1967). This could contribute to the acceleration of the subsidence by increasing the effective stress.

In addition, the oedometer tests carried out by Dan et al. (2007) sediment samples from the same area (i.e., near S1), demonstrated the action of freshwater flows in the compaction acceleration. Actually, fresh water injection during oedometer tests generates more rapid and extensive formation compared to the same tests without fluid injection. Moreover, fluid circulation would generate leaching and physicochemical reorganizations within sediments (Dan et al., 2007) inducing a greater compaction as well. The preferential water flow directions in the Var delta, towards the East and West corners of the airport platform (Potot, 2011), are in good agreement with subsiding zones, $\mathrm{S} 1$ and S3, locations. The drains, installed in those areas (Fig. 4c) to help the fluid circulation through the sediments, must also participate to increase the compaction rate. To summarize: the faster subsidence rate measured in $\mathrm{S} 1$, the uneven distribution of sediments deposits around it, the recent landslides in the area, and the steepening of flanks are all processes that could bring this section of the margin closer to destabilization.

In our analysis of the subsidence pattern, one question remains: is there any evidence of the influence of the reclaimed land on the evolution of the delta? Because our measurements are limited to land and the area reclaimed by the NCA airport defines the new coastline of the delta, it is difficult to isolate the impact of the man-made structure on the subsidence rate. However, one piece of evidence that the reclaimed lands have an influence on the compaction is the small jump of about $0.5-1 \mathrm{~mm} \mathrm{yr}^{-1}$ in the rate of subsidence at the transition between the former coastline and the reclaimed land (Fig. 4). Although small, this change can be followed along almost the whole length of the platform. In the two profiles of subsidence rate across the NCA airport (Fig. $4 \mathrm{~d}$ and e), the jump is localized at points $s$ and $s^{\prime}$, respectively. Hence, there is a detectable influence of the reclaimed lands on the subsidence of the delta, but it is difficult to evaluate how much it impacts its evolution.

\section{Conclusions}

Previous studies have shown that many river deltas, around the world, are sinking. However, the full spatial variability of the subsidence is often poorly documented. We used, here, very accurate InSAR measurement ( $1 \sigma$ error of $0.25 \mathrm{~mm} \mathrm{yr}^{-1}$ ) to show undoubtedly the ongoing subsidence of the whole Var delta. This slow deformation, between 0.5 and $1 \mathrm{~mm} \mathrm{yr}^{-1}$ in the Var valley, increases toward the sea and reaches $3 \mathrm{~mm} \mathrm{yr}^{-1}$ on the Nice airport platform built over reclaimed lands. In addition to this main subsidence pattern, three areas located on the edges of the platform have a vertical deformation up to $10 \mathrm{~mm} \mathrm{yr}^{-1}$. The main subsi- dence mechanism is the compaction of the thick Holocene sediment layer. This result is in good agreement with observations made on others deltas around the world.

Among the three areas subsiding faster than the rest of the platform, the southern tip of the airport is the main concern as steep underwater slopes border the reclaimed lands. The two others areas are either much smaller (S3) or distant from the shelf break and its steep slope (S2). By its size and location, a collapse of S1 could thus be a repetition of the 1979 landslide catastrophe. However, the measured ground deformation, that we interpret as compaction, does not imply that a catastrophic event will inevitably occur.

Through this analysis, we pointed out the impact of the overload caused by the construction of the airport build on land gained over sea. Actually, the accurate ground motion measurements show a $\sim 1 \mathrm{~mm} \mathrm{yr}^{-1}$ increase of subsidence across the border between lands and reclaimed lands. However, it is difficult to predict what would be the compaction gradient further south without the airport weight.

On a scientific perspective, tracking and understanding the seafloor deformation is the next step but would call for complex and very expensive technologies (Newman, 2011). For our study area, knowing how the inland deformation propagates offshore would help to establish the role of the reclaimed area on the delta subsidence. Combined with modelling, such data could also greatly help evaluating how much strain such reclaimed lands are able to support and how the subsidence rate will evolve in the future. Finally, as for inland landslide, a better identification of the triggering factors (such as earthquakes, fluid, and groundwater) would help to secure land reclamations.

Acknowledgements. The SAR data were provided by the European Space Agency through category-1 project 12769 . ESA retain ownership of the original Envisat SAR data. We thank Jenny Trévisan and Wanda Berolo from the Géoazur GIS department for their help to make Figs. 1 and 4. We are also thankful to Frédéric Cappa and Louis De Barros for the fruitful discussions and to Pietro Teatini for his review suggestions.

Edited by: O. Katz

Reviewed by: P. Teatini and another anonymous referee

\section{References}

Allen, J. R. L.: Salt-marsh growth and fluctuating sea level: implications of a simulation model for Flandrian coastal stratigraphy and peat-based sea-level curves, Sediment. Geol., 100, 21-45, 1995.

Anthony, E. J.: Problems of hazard perception on the steep, urbanised Var coastal floodplain and delta, French Riviera, Méditerranée, J. Mediterr. Geogr., 108, 91-97, 2007.

Anthony, E. J. and Julian, M.: The 1979 Var Delta landslide on the French Riviera: a retrospective analysis, J. Coast. Res., 13, 2735, 1997. 
Assier-Rzadkieaicz, S., Heinrich, P., Sabatier, P. C., Savoye, B., and Bourillet, J. F.: Numerical modelling of a landslide-generated tsunami: the 1979 Nice event, Pure Appl. Geophys., 157, 17071727, 2000.

Cavalié, O. and Jónsson, S.: Block-like plate movements in eastern Anatolia observed by InSAR, Geophys. Res. Lett., 41, 26-31, doi:10.1002/2013GL058170, 2014.

Cavalié, O., Doin, M.-P., Lasserre, C., and Briole, P.: Ground motion measurement in the Lake Mead area, Nevada, by differential synthetic aperture radar interferometry time series analysis: probing the lithosphere rheological structure, J. Geophys. Res., 112, B03403, doi:10.1029/2006JB004344, 2007.

Cochonat, P., Bourillet, J.-F., Savoye, B., and Dodd, L.: Geotechnical characteristics and instability of submarine slope sediments, the nice slope (NW Mediterranean Sea), Mar. Geores. Geotechnol., 11, 131-151, 1993.

Courboulex, F., Larroque, C., Deschamps, A., Kohrs-Sansorny, C., Got, C. G. J.-L., Stéphan, J. C. J.-F., Béthoux, N., Virieux, J., Brunel, D., Maron, C., Duval, A.-M., Pérez, J.-L., and Mondi, J.L.: Seismic hazard on the French Riviera: observations, interpretations and simulations, Geophys. J. Int., 170, 387-400, 2007.

Dan, G., Sultan, N., and Savoye, B.: The 1979 Nice harbour catastrophe revisited: trigger mechanism inferred from geotechnical measurements and numerical modelling, Mar. Geol., 245, 40-64, 2007.

Doin, M.-P., Lodge, F., Guillaso, S., Jolivet, R., Lasserre, C., Ducret, G., Grandin, R., Pathier, E., and Pinel, V.: Presentation of the small baseline NSBAS processing chain on a case example: the Etna deformation monitoring from 2003 to 2010 using Envisat data, ESA, SP-697, Proc. of FRINGE 2011 Workshop, 19-23 September 2011, Frascati, Italy, 2012.

Dokka, R. K.: Modern-day tectonic subsidence in coastal Louisiana, Geology, 34, 281-284, doi:10.1130/G22264.1, 2006.

Dubar, M. and Anthony, E. J.: Holocene environmental change and river-mouth sedimentation in the Baies des Anges, French Riviera, Quaternary Res., 43, 329-343, 1995.

Ericson, J. P., Vörösmarty, C. J., Dingman, S. L., Ward, L. G., and Meybeck, M.: Effective sea-level rise and deltas: causes of change and human dimension implications, Global Planet. Change, 50, 63-82, 2006.

Farr, T. G. and Kobrick, M.: Shuttle radar topography mission produces a wealth of data, Eos Trans. AGU, 81, 583-585, 2000.

Goldstein, R. M. and Werner, C. L.: Radar interferogram filtering for geophysical applications, Geophys. Res. Lett., 25, $2517-$ 2520, 1998.

Guglielmi, Y.: Gydrogéologie des aquifères Plio-Quaternaires de la Basse Vallée du Var, Thèse d'état, Académie d'Aix-Marseille, Aix-Marseille, 170 pp., 1993.

Hassoun, V., Martin, J., Migeon, S., Larroque, C., Cattaneo, A., Eriksson, M., Sanchez-Cabeza, J. A., Mercier de Lepinay, B., Liong Wee Kwong, L., Levy, I., Heimbürger, L.-E., and Miquel, J.-C.: Searching for the record of historical earthquakes, floods and anthropogenic activities in the Var Sedimentary Ridge (NW Mediterranean), Adv. Nat. Technol. Haz., 37, 571-581, 2014.

Higgins, S. A., Overeem, I., Steckler, M. S., Syvitski, J. P. M., Seeber, L., and Akhter, S. H.: InSAR measurements of compaction and subsidence in the Ganges-Brahmaputra
Delta, Bangladesh, J. Geophys. Res.-Earth., 119, 1768-1781, doi:10.1002/2014JF003117, 2014.

Hooper, A., Zebker, H., Segall, P., and Kampes, B.: A multitemporal InSAR method incorporating both persistent scatterer and small baseline approaches, Geophys. Res. Lett., 35, L16302, doi:10.1029/2008GL03465, 2008.

Ioualalen, M., Migeon, S., and Sardou, O.: Landslide tsunami vulnerability in the Ligurian Sea: case study of the 1979 October 16 Nice international airport submarine landslide and of identified geological mass failures, Geophys. J. Int., 181, 724-740, doi:10.1111/j.1365-246X.2010.04572.x, 2010.

Kelner, M., Migeon, S., Tric, E., Couboulex, F., Lebourg, A. D. T., and Taboada, A.: Recent morphological changes of the Nice Continental Slope, Eng. Geol. Soc. Terr., 4, 221-225, 2014.

Kopf, A. J., Kasten, J., and Blees, J.: Geochemical evidence for groundwater-charging of slope sediments: the Nice airport 1979 landslide and tsunami revisited, Adv. Nat. Technol. Haz., 28, 203-214, 2010.

Larroque, C., Mercier de Lépinay, B., and Migeon, S.: Morphotectonic and fault earthquake relationships along the northern Ligurian margin (western Mediterranean) based on high resolution, multibeam bathymetry and multichannel seismic-reflection profiles, Mar. Geophys. Res., 32, 163-179, 2011.

Larroque, C., Scotti, O., and Ioualalen, M.: Reappraisal of the 1887 Ligurian earthquake (western Mediterranean) from macroseismicity, active tectonics and tsunami modelling, Geophys. J. Int., 190, 87-104, 2012.

Leynaud, D. and Sultan, N.: 3-D slope stability analysis: A probability approach applied to the nice slope (SE France), Mar. Geol., 269, 89-106, 2010.

Long, A. J., Waller, M. P., and Stupples, P.: Driving mechanisms of coastal change: peat compaction and the destruction of late Holocene coastal wetlands, Mar. Geol., 225, 63-84, doi:10.1016/j.margeo.2005.09.004, 2006.

López-Quiroz, P., Doin, M.-P., Tupin, F., Briole, P., and Nicolas, J.-M.: Time series analysis of Mexico City subsidence constrained by radar interferometry, J. Appl. Geophys., 69, 1-15, doi:10.1016/j.jappgeo.2009.02.006, 2009.

Mazzotti, S., Lambert, A., Van der Kooij, M., and Mainville, A.: Impact of anthropogenic subsidence on relative sealevel rise in the Fraser River delta, Geology, 37, 771-774, doi:10.1130/G25640A.1, 2009.

Migeon, S., Cattaneo, A., Hassoun, V., Larroque, C., Corradi, N., Fanucci, F., Dano, A., Lepinay, B., Sage, F., and Gorini, C.: Morphology, distribution and origin of recent submarine landslides of the Ligurian Margin (North-western Mediterranean): some insights into geohazard assessment, Mar. Geophys. Res., 32, 225 243, doi:10.1007/s11001-011-9123-3, 2011.

Migeon, S., Cattaneo, A., Hassoun, V., Dano, A., Casedevant, A., and Ruellan, E.: Failure processes and gravity-flow transformation revealed by high-resolution AUV swath bathymetry on the Nice continental slope (Ligurian Sea), Adv. Nat. Technol. Haz., 31, 451-461, 2012.

Milliman, J. D., Broadus, J. M., and Gable, F.: Environmental and economic implications of rising sea-level and subsiding deltas: the Nile and Bengal examples, Ambio, 18, 340-345, 1989.

Mulder, T., Tisot, J.-P., Cochonat, P., and Bourillet, J.-F.: Regional assessment of mass failure events in the Baie des Anges, Mar. Geol., 122, 29-45, doi:10.1016/0025-3227(94)90203-8, 1994. 
Mulder, T., Savoye, B., and Syvitski, J. P. M.: Numerical modelling of a mid-sized gravity flow: the 1979 Nice turbidity current (dynamics, processes, sediment budget and seafloor impact), Sedimentology, 44, 305-326, 1997.

Newman, A. V.: Hidden depths, Nature, 474, 441-443, doi:10.1038/474441a, 2011.

Ollié, J.-P.: L'extension sud de l'aéroport international de Nice Côte d'Azur, Le point sur les travaux, Rev. Gen. Routes Aerodr., 588, 2-11, 1982.

Potot, C.: Etude hydrochimique du système aquifère de la basse vallée du Var. Apport des éléments traces et des isotopes ( $\mathrm{Sr}, \mathrm{Pb}$, $\left.\delta^{18} \mathrm{O}\right),{ }^{226,228} \mathrm{Ra}$ ), Thèse de doctorat, Université de Nice-Sophia Antipolis, Nice, 2011.

Rosen, P. A., Hensley, S., Peltzer, G., and Simons, M.: Updated repeat orbit interferometry package released, EOS Trans. AGU, 85, p. 47, doi:10.1029/2004EO050004, 2004.

Sahal, A. and Lemahieu, A.: The 1979 Nice airport tsunami: mapping of the flood in Antibes, Nat. Hazards, 56, 833-840, 2011.

Stegmann, S., Sultan, N., Kopf, A., Apprioual, R., and Pelleau, P.: Hydrogeology and its effect on slope stability along the coastal aquifer of Nice, France, Mar. Geol., 280, 168-181, 2011.

Sultan, N., Savoye, B., Jouet, G., Leynaud, D., Cochonat, P., Henry, P., and Kopf, A.: Investigation of a possible submarine landslide at the Var delta front (Nice continental slope, southeast France), Can. Geotech. J., 47, 486-496, 2010.
Syvitski, J. P. M., Kettner, A. J., Hutton, I. O. E. W. H., Hannon, M. T., Brakenridge, G. R., Day, J., Vorosmarty, C., Saito, Y., Giosan, L., and Nicholls, R. J.: Sinking deltas due to human activities, Nat. Geosci., 2, 681-686, doi:10.1038/NGEO629, 2009.

Teatini, P., Tosi, L., and Strozzi, T.: Quantitative evidence that compaction of Holocene sediments drives the present land subsidence of the Po Delta, Italy, J. Geophys. Res., 116, B08407, doi:10.1029/2010JB008122, 2011.

Terzaghi, K. and Peck, R.: Soil Mechanics in Engineering Practice, John Wiley, New York, 1967.

Törnqvist, T., Wallace, D. J., Storm, J. E. A., Wallinga, J., van Dam, R. L., Derksen, M. S., Klerk, C. J. W., Meijneken, C., and Snijders, E. M.: Mississippi Delta subsidence primarily caused by compaction of Holocene strata, Nat. Geosci., 1, 173-176, doi:10.1038/ngeo129, 2008.

Wöppelmann, G., Le Cozannet, G., de Michele, M., Raucoules, D., Cazenave, A., Garcin, M., Hanson, S., Marcos, M., and Santamaría-Gómez, A.: Is land subsidence increasing the exposure to sea level rise in Alexandria, Egypt?, Geophys. Res. Lett., 40, 2953-2957, doi:10.1002/grl.50568, 2013. 